\title{
Injection Site
}

National Cancer Institute

\section{Source}

National Cancer Institute. Injection Site. NCI Thesaurus. Code C77680.

The anatomic site at which a medication or a vaccine is injected. 